Metallophysics and Advanced Technologies

металофіз. новітні технол.

Metallofiz. Noveishie Tekhnol.

2020, vol. 42, No. 10 , pp. 1335-1346

https://doi.org/10.15407/mfint.42.10.1335

Reprints available directly from the publisher

CRYSTAL-LATTICE DEFECTS

PACS numbers: 64.60.De, 64.60.Ej, 66.30.Ny, 66.30.Pa, 68.35.bd, 81.30.Hd

\title{
Flux-Driven Lateral Grain Growth during Reactive Diffusion
}

\author{
A. M. Gusak
}

Bohdan Khmelnytsky National University of Cherkasy,

81 Shevchenko Blvd.,

UA-18031 Cherkasy, Ukraine

Lateral grain growth accompanies intermetallic compound growth. Moreover, it can be induced by reactive phase transformation at low temperatures (at frozen bulk diffusion). In its turn, the evolution of grain size (at low temperature) influences the rate of diffusive reaction. This synergy of the Reaction-Driven Grain Growth and Diffusion-Controlled Reaction is analysed. Power laws for the intermetallic compound growth with time exponent $\mathbf{0 . 4}$ and the lateral grain growth with time exponent 0.2 are predicted.

Key words: reactive diffusion, grain growth, kinetics, power law.

Ріст прошарку проміжної фази у процесі реакційної дифузії зазвичай супроводжується латеральним ростом зерен. Більше того, латеральний ріст зерен може виявитись індукованим не лише кривизною меж зерен, але і самим процесом реакційної дифузії. Своєю чергою, еволюція латеральних розмірів зерен (за низької температури і замороженої дифузії в об'ємі зерен) впливає на кінетику росту фазового прошарку. Досліджено саме таку синергію росту фазового прошарку, індукованого реакцією росту зерен і контрольованого дифузією. Прогнозовано градієнт латеральних розмірів зерен вздовж фазового прошарку, степеневі закони росту товщини фази і розмірів зерен зі степенями відповідно 0,4 і 0,2.

Ключові слова: реакційна дифузія, ріст зерен, кінетика, степеневий закон.

(Received March 6, 2020)

Corresponding author: Andriy Mykhaylovych Gusak

E-mail: amgusak@ukr.net

Citation: A. M. Gusak, Flux-Driven Lateral Grain Growth during Reactive Diffusion, Metallofiz. Noveishie Tekhnol., 42, No. 10: 1335-1346 (2020),

DOI: $10.15407 /$ mfint.42.10.1335. 
Understanding of the kinetics of intermetallic compound (IMC) growth during diffusive interactions between solids or between solid and liquid is crucial for all kinds of interfacial bonding. Kinetically, two marginal cases are discussed usually: diffusion-controlled reactions or interfacial reaction controlled reactions, where the relation between the product thickness $\Delta X$ and time follows either $(\Delta X)^{2} \sim t$ or $\Delta X \sim t[1-$ $3]$ However, with further 'going nano', various reactive kinetics are reported, especially the grain growth accompanying the layered IMC growth. Below we suggest a synergetic analysis of grain growth in diffusive interfacial reactions, taking into account not only influence of grain growth on the total interdiffusion flux, but as well the possibility of inverse influence of this flux on the lateral grain growth in the bamboo structures.

We begin by reminding the standard model of diffusion-controlled growth of an intermetallic layer having the parabolic law for thickness: $\Delta X=k t^{1 / 2}[1-3]$. In Fig. 1 flux balance equations for the moving interfaces of the single growing IMC layer under steady-state approximation lead to the well-known growth equation [4]:

$$
\frac{d \Delta X^{i}}{d t}=\left(\frac{1}{C_{B}^{i / A}}+\frac{1}{1-C_{B}^{i / B}}\right) D^{(i)} \frac{C_{B}^{i / B}-C_{B}^{i / A}}{\Delta X^{i}} \approx \frac{D^{(i)}}{C^{i}\left(1-C^{i}\right)} \frac{\Delta C^{i}}{\Delta X^{i}}
$$

and

$$
\Delta C^{i}=C_{B}^{i / B}-C_{B}^{i / A}<<1, \quad C_{B}^{i / B} \approx C_{B}^{i / A} \equiv C^{i}, \quad D^{(i)}=\frac{1}{\Delta C^{i}} \int_{C_{B}^{i / A}}^{C_{B}^{i / B}} \tilde{D}(C) d C,
$$

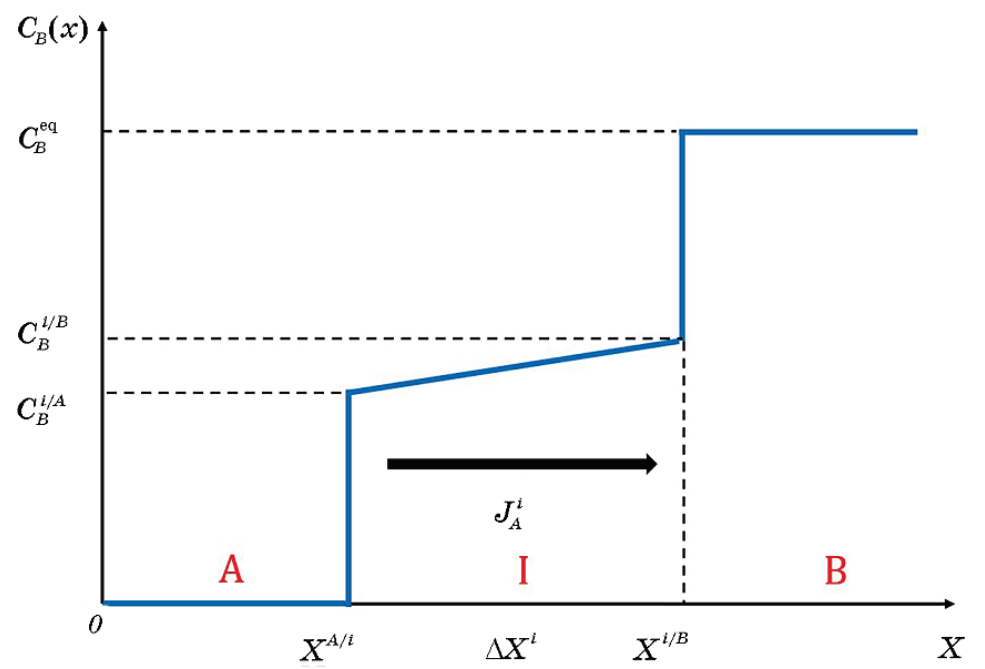

Fig. 1. Concentration profile in reactive diffusion with single growing intermediate phase ' $i$ '. 
$D_{W} \equiv \int_{C_{B}^{i / A}}^{C_{B}^{i / B}} \tilde{D}(C) d C=D^{(i)} \Delta C^{i}$ is Wagner diffusivity [5, 6].

The major reason in introducing the Wagner diffusivity is to overcome the difficulty of describing the phases with almost vanishing concentration range $\Delta C^{i} \approx 0$.

In Eq. (1) we made the typical approximation, where the solubility of $A$ in $B$ and of $B$ in $A$ are neglected, and it has the obvious parabolic solution

$$
\Delta X^{i} \approx \sqrt{\frac{2 D^{(i)} \Delta C^{i}}{C^{i}\left(1-C^{i}\right)} t} .
$$

Experimentally, various time laws are obtained $\left(\Delta X \sim t^{n}\right)$ with the time exponents $n$ changing from $n=1$ to at least $n=0.25$ [7-10].

Parabolic law $(n=0.5)$ is known for reactions at relatively high temperatures when the IMC growth is controlled by the bulk interdiffusivity. Then, time exponent $n=1$ is typically valid during some initial stage of the reaction and is usually prescribed to interfacecontrolled kinetics [11] or to the limited efficiency of vacancy sinks at the interfaces [12].

Time exponents less than $\mathbf{0 . 5}$ are usually related to a combination of bulk and grain boundary diffusion or just grain boundary diffusion with a frozen bulk diffusion. For intermediate temperatures, one might expect the Fisher-like regime, controlled by grain-boundary diffusion with simultaneous sucking out the diffusants into the bulk of the grains.

In many cases the reactive diffusion may proceed at low temperatures when bulk diffusion is practically frozen, so that the IMC phase growth proceeds due to diffusion along grain boundaries as well as the lateral diffusion along interfaces. In this case the non-parabolic regime may be related to the lateral grain growth in the IMC during the reactive diffusion along the grain boundaries. Below we distinguish two models of such reaction kinetics.

\section{MODEL 1}

In the Model 1 one may assume that the growing IMC has a bambootype structure with cylindrical grains of height $\Delta X$, mean radius $R$, and the grain boundary thickness $\delta$, see Fig. 2. Very similar model is discussed in [10] (see Eqs. (7)-(12) in [10]).

For simplicity, assume that the lateral size of each grain is the same along the phase layer and changes with time simultaneously in the same way in all sections. In other words, $R$ depends on time but does 
not depend on coordinate within phase. Then the ratio between the fast diffusion path along the cross-section of the grain boundaries and the full cross-section of the grain is

$$
\frac{1}{2} \frac{\delta 2 \pi R}{\pi R^{2}}=\frac{\delta}{R},
$$

so that the effective diffusivity across the layer is

$$
D^{\text {effective }}(t) \approx \frac{\delta}{R(t)} D_{\mathrm{GB}}^{i} .
$$

Substitution of Eq. (3) into Eq. (1) gives:

$$
\frac{d \Delta X^{i}}{d t} \approx \frac{\delta D_{\mathrm{GB}}^{i}}{C^{i}\left(1-C^{i}\right)} \frac{1}{R} \frac{\Delta C^{i}}{\Delta X^{i}} .
$$

Let us assume that the lateral grain size $2 R$ in the IMC grows with time according to power law $R=A t^{m}, m<1$. Then,

$$
\begin{gathered}
\left(\Delta X^{i}\right)^{1} d \Delta X^{i} \approx \frac{\delta D_{G B}^{i} \Delta C^{i}}{C^{i}\left(1-C^{i}\right)} \frac{d t}{A t^{m}}, \\
\Delta X=\left(\frac{2 \delta D_{\mathrm{GB}}^{i}}{(1-m) C^{i}\left(1-C^{i}\right) A}\right)^{1 / 2} t^{\frac{1-m}{2}} .
\end{gathered}
$$

For example, if the grain growth obeys parabolic law $(m=0.5)$, typical for normal grain growth, then the time exponent for phase growth becomes $n=(1-1 / 2) / 2=0.25$. Another familiar possibility is similar to

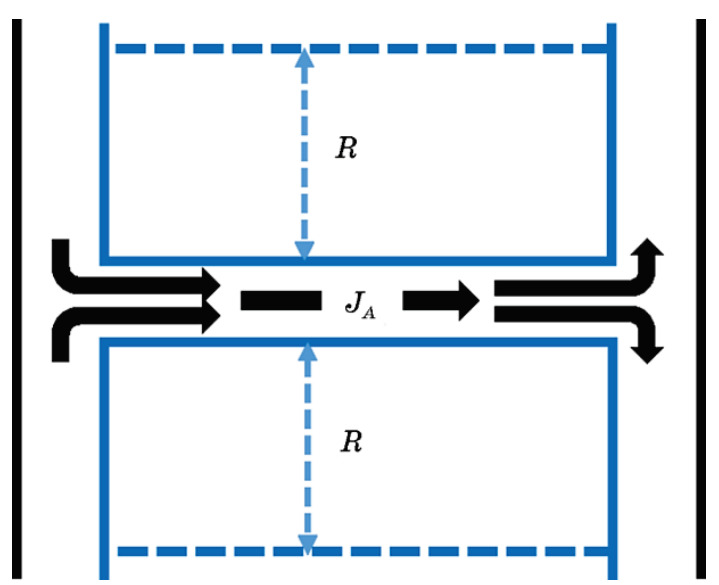

Fig. 2. Diffusion-controlled phase growth by diffusion along GB in the bamboo structure. 
Flux-Driven Ripening [13]: $m=1 / 3, n=(1-1 / 3) / 2=1 / 3$.

\section{MODEL 2}

So far in this article we considered the lateral grain growth as independent from the IMC growth in thickness. Now we will consider the mechanisms where these two factors act synergetically. The reason is that in our case grain growth proceeds in the open system, so the growing layer can develop under gradients of chemical potentials as well as under passing fluxes. It is demonstrated in [13-18] that the fluxdriven morphology evolution in open systems can demonstrate quite a different behaviour from analogic morphology evolution in closed systems. For example, Flux-Driven Ripening (FDR) in soldering reaction proceeds (contrary to the conventional ripening with decreasing interface area and almost constant volume) with almost constant interface area but growing volume [13]. Flux-Driven lateral Grain Growth (FDGG) during thin film deposition also may leave the total grainboundary area constant and, depending on temperature, may lead to linear or parabolic dependence of mean grain size on the film thickness $[14,16]$. Flux-Driven Nucleation [15] and Flux-Driven Cellular Precipitation $[17,18]$ demonstrate the influence of external flux on nucleation at interfaces and on precipitation at frozen bulk diffusion.

Here we will try to apply flux-driven approach to the lateral grain growth in IMC at frozen bulk diffusion and at frozen conventional grain growth. Namely, in Model 2 we assume that the normal curvature-driven lateral grain growth is also frozen and the only way to change the grain size of the growing IMC layer at low temperatures is to chose the host grain for atoms arriving via the grain boundary to the joint of GB with interface, see Fig. 3.

In Model 2 we assume that the IMC growth proceeds mainly due to transfer of $A$ atoms via GBs (grain-boundaries in IMC) from the triple junctions ' $A /($ GB in IMC)' to the triple junctions '(GB in IMC) $/ B$ ' with a consequential lateral redistribution along this interface and reaction with $B$. Driving force of this process coincides with the driving force of reaction, which is the gradient of chemical potentials. The only place (moment) where the capillary forces and corresponding GibbsThomson potential $\gamma \Omega / R$ may play a role, is the redistribution of the atoms arriving at the joint, between the neighbouring grains. We also assume that the diffusivity along lateral interfaces between phase layer and reacting materials is much larger than diffusivity along the grain boundaries (taking into account that the disorder at interfaces is expected to be stronger than at grain boundaries). Such assumption is not very well based. More general model with account of both finite diffusivities and, respectively, with curved moving interfaces between the triple junctions of grain-boundaries, will be presented elsewhere. 
$A$

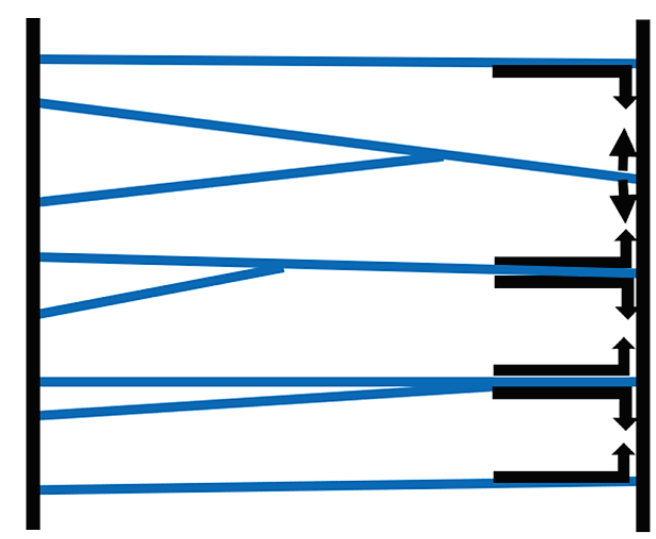

B

Fig. 3. Lateral grain growth induced by phase growth.

If lateral redistribution proceeds faster than the transport through the IMC layer, we may use the Boltzmann distribution for finding the fraction of atoms going to various grains or to the two opposite sides of the GB junction with interface. The difference between thermodynamic driving forces of reactions at the two sides of the curved junction with curvature radius $r$ is

$$
\frac{\gamma \Omega}{r}=\frac{\gamma \Omega}{2 r}-\left(-\frac{\gamma \Omega}{2 r}\right) .
$$

Therefore, the probabilities of sticking of the incoming atom to one of the adjacent (to the junction with curvature radius $r$ ) grains are equal to

$$
p_{+}=\frac{\mathrm{e}^{\frac{\gamma \Omega}{2 r k T}}}{\mathrm{e}^{\frac{\gamma \Omega}{2 r k T}}+\mathrm{e}^{-\frac{\gamma \Omega}{2 r k T}}}
$$

and

$$
p_{-}=\frac{-\mathrm{e}^{\frac{\gamma \Omega}{2 r k T}}}{\mathrm{e}^{\frac{\gamma \Omega}{2 r k T}}+\mathrm{e}^{-\frac{\gamma \Omega}{2 r k T}}}
$$

Then, the average local lateral shift of the curved grain boundary junction with interface after the formation of a new atomic layer of thickness $d$ will be equal to

$$
\Delta y=d \tanh \left(\frac{\gamma \Omega}{2 r k T}\right) .
$$

For $r$ larger than $100 \mathrm{~nm}$ and temperature higher than $400 \mathrm{~K}$ 


$$
\frac{\gamma \Omega}{2 r k T}<<1 \Rightarrow \tanh \left(\frac{\gamma \Omega}{r k T}\right) \approx \frac{\gamma \Omega}{2 r k T} .
$$

The inverse mean curvature radius $r$ is proportional to the mean grain size (see, for example, [19]):

$$
\frac{1}{r}=b \frac{1}{R}
$$

with $b$ of the order of magnitude about 1 . Namely, according to [19], mean grain intercept $\lambda$ for grain growth in $\mathrm{Al}$ is equal to $0.31 r$. If one takes approximately that the mean grain intercept is half of grain size $(R=(1 / 2) 2 R)$, then we may estimate $b \approx 0.3$.

Combing Eqs. (7) and (8), we obtain the important relation:

$$
\frac{d R}{d \Delta X} \approx b \frac{\gamma \Omega}{2 k T} \frac{1}{R} .
$$

It is important because Eq. (9) relates the grain size not to the time but directly to the IMC layer thickness. If we approximate the initial condition as $R \approx 0$ at $\Delta X \approx 0$, then Eq. (9) immediately gives:

$$
R^{2} \approx 2 b \frac{\gamma \Omega}{2 k T} \Delta X, \quad R \approx \sqrt{b \frac{\gamma \Omega}{k T} \Delta X} .
$$

Substitution of Eq. (10) into Eq. (4), we obtain the new time dependence for IMC growth (which has never been predicted before but found experimentally).

$$
\frac{d \Delta X^{i}}{d t} \approx \frac{\delta D_{\mathrm{GB}}^{i}}{C^{i}\left(1-C^{i}\right)} \frac{1}{\sqrt{b \gamma \Omega /(k T)}} \frac{\Delta C^{i}}{\left(\Delta X^{i}\right)^{3 / 2}},
$$

so that

$$
\Delta X^{i} \approx \frac{5 \delta D_{\mathrm{GB}}^{i} \Delta C^{i}}{2 C^{i}\left(1-C^{i}\right)} \sqrt{\frac{k T}{b \gamma \Omega}} t^{2 / 5} .
$$

Thus, the time law for grain size will be

$$
R \approx \sqrt{\sqrt{b \gamma \Omega /(k T)} \frac{5 \delta D_{\mathrm{GB}}^{i} \Delta C^{i}}{2 C^{i}\left(1-C^{i}\right)} t^{2 / 5}} \sim t^{1 / 5} .
$$

\section{MORE RIGOROUS VERSION OF MODEL 2}

Strictly speaking, Eqs. (12), (13) are approximate because, according to Eqs. (9) and (10), the lateral grain size is not the same along the IMC 
thickness, but it varies with IMC thickness and it is described by an increasing function $R(x), 0<x<\Delta X$. Let $R(x=0)=R_{0}$ at the left boundary, then

$$
R(x) \approx \sqrt{R_{0}{ }^{2}+\frac{b \gamma \Omega}{k T} x}, 0<x<\Delta X .
$$

In the steady state approximation, the flux should be constant along $x$ :

$$
\Omega J=\frac{\delta D_{\mathrm{GB}}^{i}}{\sqrt{{R_{0}}^{2}+\frac{b \gamma \Omega}{k T} x}} \frac{d C}{d x}=\text { const. }
$$

Now we follow the analysis of quasi-steady-state flux with variable kinetic coefficients in [20]:

$$
\begin{aligned}
& \Omega J=\frac{\delta D_{\mathrm{GB}}^{i}}{R(x)} \frac{d C}{d x}=\text { const } \equiv \frac{\Omega J \int_{0}^{\Delta X} R(x) x}{\int_{0}^{\Delta X} R(x) d x}=\frac{\int_{0}^{\Delta X} \Omega J R(x) d x}{\int_{0}^{\Delta X} R(x) d x}= \\
& =\frac{\int_{0}^{\Delta X} \delta D_{\mathrm{GB}}^{i} d C}{\int_{0}^{\Delta X} \sqrt{R_{0}{ }^{2}+[b \gamma \Omega /(k T)] x} d x}=\frac{\delta D_{\mathrm{GB}}^{\text {Wagner }}}{\frac{2}{3} \sqrt{b \gamma \Omega / k T}\left[\Delta X+k T R_{0}^{2} /(b \gamma \Omega)\right]^{3 / 2}} .
\end{aligned}
$$

Thus,

$$
\frac{d \Delta X^{i}}{d t} \approx \frac{1}{C^{i}\left(1-C^{i}\right)} \frac{\delta D_{\mathrm{GB}}^{\text {Wagner }}}{\frac{2}{3} \sqrt{b \gamma \Omega /(k T)}\left[\Delta X+k T R_{0}^{2} /(b \gamma \Omega)\right]^{3 / 2}} .
$$

It gives

$$
\left(\Delta X^{i}+\frac{k T R_{0}^{2}}{b \gamma \Omega}\right)^{5 / 2} \approx\left(\Delta X_{0}+\frac{k T R_{0}^{2}}{b \gamma \Omega}\right)^{5 / 2}+\frac{15}{4} \frac{\delta D_{\mathrm{GB}}^{i} \Delta C^{i}}{C^{i}\left(1-C^{i}\right)} \sqrt{\frac{k T}{b \gamma \Omega}} t .
$$

Simple power laws for kinetics of phase growth and grain growth can be obtained only in the marginal case when on take initial zero conditions both for phase thickness and for mean grain size: $\Delta X_{0} \approx 0, R_{0} \approx 0$. Then

$$
\Delta X^{i} \approx\left(\frac{15}{4} \frac{\delta D_{\mathrm{GB}}^{i} \Delta C^{i}}{C^{i}\left(1-C^{i}\right)} \sqrt{\frac{k T}{b \gamma \Omega}} t\right)^{2 / 5}
$$




$$
R\left(x=\Delta X^{i}\right) \approx \sqrt{b \frac{\gamma \Omega}{k T} \Delta X^{i}} \approx\left(\frac{15 \delta D_{\mathrm{GB}}^{i} \Delta C^{i}}{4 C^{i}\left(1-C^{i}\right)}\left(b \frac{\gamma \Omega}{k T}\right)^{2}\right)^{1 / 5} t^{1 / 5} .
$$

So, for the mean lateral size, the only difference of this more rigorous approach, in comparison with Eq. (12b), is the factor $3 / 2$.

Approximation $D_{A} \gg D_{B}$ in our analysis is made just for simplification: in this case, in the lattice reference frame, the reaction proceeds only between incoming new atoms $A$ and the material $B$ at the 'righthand' side of the growing phase (Fig. 3), so that the lateral grain size increases at the right-hand side of the growing phase. In general case, $R(x)$ is expected to be nonmonotonic with minimum around Kirkendall plane, which (in case of single-phase growth) is expected to be situated within phase layer, closer to the fast diffusant material. Experimentally, different morphologies at different sides of Kirkendall plane, as well as between bifurcated Kikendall planes, are found by the team of Frans van Loo at Eindhoven (see, for example, [21]). In particular, nucleation of new grains of Cu3Sn near the interface $\mathrm{Cu} / \mathrm{Cu} 3 \mathrm{Sn}$ (are $\mathrm{Cu}$ is a faster diffusant) is found in [22]. This more general case needs longer and more complicated math and will be considered elsewhere.

\section{ACCOUNT OF NON-ZERO INITIAL CONDITION FOR MEAN LATERAL SIZE}

So far we are describing the phase and grain growth with formally zero initial values for phase layer thickness and for grain size. Such approximation is necessary to obtain simple power time dependence. It would be OK for phase thickness and grain sizes of tens of microns, but not OK if the phase thickness is a few hundreds of nanometres and grain sizes about hundred nanometres and less. In this case it may be important to take the initial conditions into account. We will treat the morphology after nucleation stage as an initial condition.

In many cases the nucleation of new intermediate phase in various places of interface is followed by fast lateral growth leading to formation of thin initial continuous phase layer with initial thickness up to about 10 nanometres and of pancake-type grains with lateral size larger than the thickness [23, 24]. Thus, we should modify the initial conditions as $\Delta X^{i}(t=0)=\Delta X_{0}, R(t=0)=R_{0}$.

Using non-dimensional variables

$$
\tau=\left(\frac{k T}{b \gamma \Omega}\right)^{3} \frac{\delta D_{\mathrm{GB}}^{i} \Delta C^{i}}{C^{i}\left(1-C^{i}\right)} t, \quad x=\left(\frac{k T}{b \gamma \Omega}\right)^{2}\left(\Delta X_{i}\right)^{2}, \quad y=\left(\frac{k T}{b \gamma \Omega}\right)^{2} R^{2},
$$

one may convert Eqs. (4), (9) into 


$$
\frac{d x}{d t}=\frac{1}{\sqrt{y}}, \frac{d y}{d x}=\frac{1}{2 \sqrt{x}} \Rightarrow \frac{d y}{d t}=\frac{1}{\sqrt{x y}}, x(t=0)=x_{0}, y(t=0)=y_{0} .
$$

Then time exponents are found as

$$
n=\frac{d \ln \sqrt{x}}{d \ln \tau}=\frac{1}{2} \frac{\tau}{x} \frac{d x}{d \tau}, \quad m=\frac{d \ln \sqrt{y}}{d \ln \tau}=\frac{1}{2} \frac{\tau}{y} \frac{d y}{d \tau} .
$$

Typical numeric solution of Eqs. (17), (18) for the dependences $n x^{1 / 2}$, $m x^{1 / 2}$ of time exponents on the dimensionless phase layer thickness $x^{1 / 2}$ with initial conditions $x_{0}=0.25, y_{0}=1$ is shown at Fig. 4 .

In this case the exponent $m$ increases to 0.20 and exponent $n$-to 0.4 in the process of phase growth.

\section{CONCLUSIONS}

Two models of simultaneous solid-state reaction via grain-boundary diffusion and lateral grain growth are compared. In the already known Model 1 the lateral grain growth in compound layer proceeds independently on phase layer growth. If this growth is curvature-driven, if it proceeds normally without solute drag, then the power law for grain growth should be $R \sim t^{1 / 2}(m=0.5)$, and power law for phase growth should be $\Delta X \sim t^{1 / 4}(n=0.25)$. In case of the Flux-Driven ripening, Model 1 gives $n=m=1 / 3$. In Model 2 the lateral grain growth proceeds only in the interface region and is driven by the flux coming to this interface of the growing phase layer. Such flux-driven lateral grain growth during solid state reaction at frozen bulk diffusion should provide power laws, Eqs. (17), (18), with time exponents $m=0.20$ for lat-
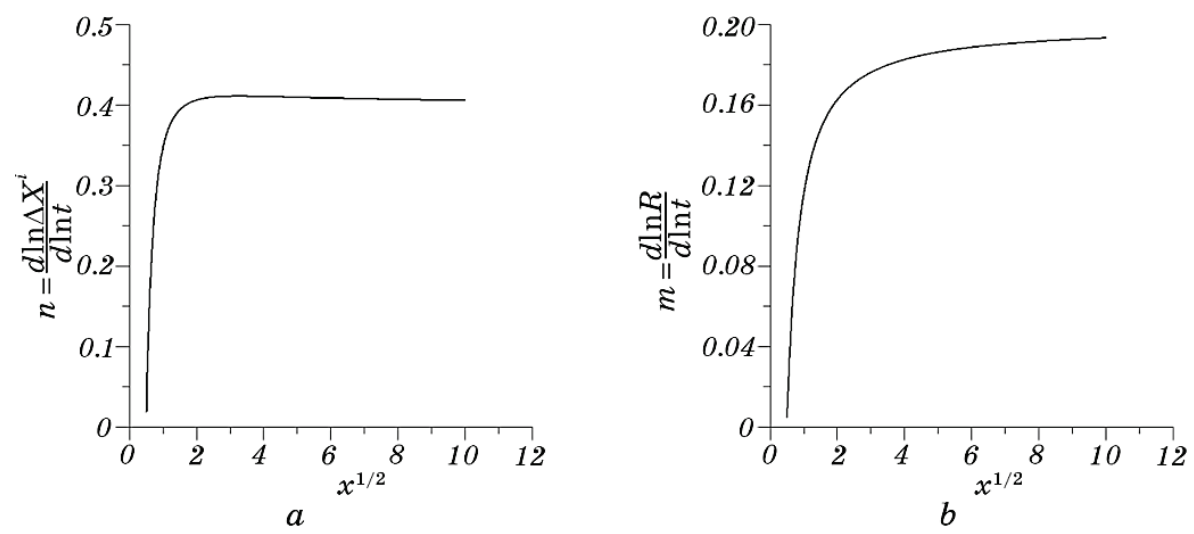

Fig. 4. Dependences of exponents $n(a)$ and $m(b)$ on the dimensionless phase layer thickness $\sqrt{x}$. 
eral grain size and $n=0.40$ for phase width. It would be interesting for experimentalists also to measure the possible gradient of the lateral grain size, predicted by Model 2 .

Author acknowledges the support of the Ministry of Education and Science of Ukraine (project No. 0118U003861).

\section{REFERENCES}

1. J. M. Poate, K. N. Tu, and J. W. Mayer, Thin Films: Interdiffusion and Reactions (New York: John Wiley and Sons: 1978).

2. K. P. Gurov, B. A. Kartashkin, and Y. E. Ugaste, Interdiffusion in Multiphase Metallic Systems (Moscow: Nauka: 1981) (in Russian).

3. F. J. J. van Loo, Prog. Solid State Chem., 20(1): 47 (1990).

4. A. M. Gusak, T. V. Zaporozhets, Y. O. Lyashenko, S. V. Kornienko, M. O. Pasichnyy, and A. S. Shirinyan, Diffusion-Controlled Solid State Reactions: in Alloys, Thin-Films, and Nanosystems (New York: John Wiley and Sons: 2010).

5. C. Wagner, Acta Metall., 17, Iss. 2: 99 (1969).

6. A. M. Gusak and N. Storozhuk, Metallofiz. Noveishie Tekhnol, 41, No. 5: 583 (2019).

7. N. Odashima, O. Minho, and M. Kajihara, J. Electronic Mater., 49: 1568 (2019).

8. T. Yamada, K. Miura, M. Kajihara, N. Kurokawa, and K. Sakamoto, Mater.Sci.Eng. A, 390, Iss. 1-2: 118 (2005).

9. M. Mita, K. Miura, T. Takenaka, M. Kajihara, N. Kurokawa, and K. Sakamoto, Mater.Sci. Eng.: B, 126, Iss. 1: 37 (2006).

10. G. Ghosh, Acta Mater., 48, Iss. 14: 3719 (2000).

11. U. Gösele and K. N. Tu, J.Appl. Phys., 53: 3252 (1982).

12. A. M. Gusak and K. P. Gurov, Proc. of an International Conference PTM'94 'Solid-to-Solid Phase Transformations' (1994).

13. A. M. Gusak and K. N. Tu, Phys. Rev. B, 66, Iss. 11: 115403 (2002).

14. K. N. Tu, A. M. Gusak, and I. Sobchenko, Phys. Rev. B, 67, Iss. 24: 245408 (2003).

15. A. M. Gusak, F. Hodaj, and G. Schmitz, Philos. Mag. Lett., 91, Iss. 9: 610 (2011).

16. A. M. Gusak, C. Chen, and K. N. Tu, Philos. Mag., 96, Iss. 13: 1318 (2016).

17. A. Gusak, R. Abdank-Kozubski, and D. Tyshchenko, Diffusion Foundations, 5: 229 (2015).

18. A. Gusak and N. Storozhuk, Handbook of Solid State Diffusion (Eds. A. Paul and S. Divinski) (Elsevier: 2017) vol. 2, p. 37.

19. B. R. Patterson and Y. Liu, Metall. Trans. A, 23, Iss. 9: 2481 (1992).

20. A. M. Gusak and M. V. Yarmolenko, J.Appl. Phys., 73, Iss. 10: 4881 (1993).

21. M. J. H. van Dal, A. M. Gusak, C. Cserháti, A. A. Kodentsov, and F. J. J. Van Loo, Phys. Rev. Lett., 86, Iss. 15: 3352 (2001).

22. P. J. Shang, Z. Q. Liu, X. Y. Pang, D. X. Li, and J. K. Shang, Acta Mater., 57, 
Iss. 16: 4697 (2009).

23. K. R. Coffey, L. A. Clevenger, K. Barmak, D. A. Rudman, and C. Thompson, Appl. Phys. Lett., 55, Iss. 9: 852 (1989).

24. A. M. Gusak, F. Hodaj, and A. O. Bogatyrev, J. Phys.: Condensed Matter., 13, Iss. 12: 2767 (2001). 